\title{
WORLDWIDE DISTRIBUTION OF GROUP VELOCITY OF MANTLE RAYLEIGH WAVES AS DETERMINED BY SPHERICAL HARMONIC INVERSION
}

\author{
By Ichiro Nakanishi and Don L. Anderson
}

\section{ABSTRACT}

\begin{abstract}
We have determined the worldwide distribution of group velocity of mantle Rayleigh waves for periods between 100 and $300 \mathrm{sec}$ without assuming any regionalization. Group slowness $1 / u(\theta, \phi)$ is expressed by spherical harmonics, and the coefficients, up to angular order 7 , have been determined from travel times of Rayleigh waves by a least-squares method. From these, $u(\theta, \phi)$ has been synthesized. Since we cannot obtain information about the odd terms of the expansion from one circuit measurements around the world, we have used group velocities of mainly $R_{2}$ and $R_{3}$. The overall pattern of $u(\theta, \phi)$ for periods between 100 and $200 \mathrm{sec}$ is consistent with results of previous pure-path and regional studies. Group velocities for tectonically active regions are low, and those of the shields and the northwestern Pacific are high.
\end{abstract}

\section{INTRODUCTION}

It is well known that if we express the aspherical perturbation of surface wave velocity over the Earth's surface in terms of a spherical harmonic expansion, we cannot determine the odd terms of the expansion from one circuit (great-circle) measurments around the world (Backus, 1964). The situation is the same for the analysis of the location of unresolved multiplets in normal mode spectra if we use first-order perturbation theory (Jordan, 1978). This is one reason why previous investigators have adopted a pure-path technique in studying worldwide lateral variation of surface wave velocity (Toksöz and Anderson, 1966; Kanamori, 1970; Dziewonski, 1971; Wu, 1972; Okal, 1977; Mills, 1978; Nakanishi, 1979; Lévêque, 1980), since Toksöz and Anderson (1966) first used this technique for the analysis of greatcircle Love waves. This approach, however, makes it difficult to compare the seismic data with the data for geoid and heat flow, which have been presented in terms of spherical harmonic expansions (e.g., Chapman and Pollack, 1975; Wagner et al., 1977). The spherical harmonic representation of the seismic data has some advantages over the pure-path representation. It makes it possible to compare global seismic data directly with the geoid and heat flow. Another advantage is that if we know the coefficients of the harmonics and we assume that the aspherical perturbation from a spherically averaged earth model is small, linearization of the inverse problem of surface wave data makes it easy to construct three-dimensional models of the Earth's mantle. Also, anomalous regions of the globe cannot be discovered with an a priori regionalization. These advantages are the motivation of this study.

As mentioned above, the one circuit measurements (e.g., $R_{2}-R_{4}$ ) of surface wave velocity cannot be used for the present purpose. To avoid this difficulty, we adopt the one-station method for the measurments of group velocity of long-period Rayleigh waves. The use of the spherical harmonic method for this application is not new. Sato and Santo (1969) first used this technique for studying the worldwide distribution of group velocity of 30-sec Rayleigh wave (Satô, 1978).

\section{SPHERICAL HaRmonic INVERsion}

This study makes some assumptions about the propagation of surface waves on the Earth. First, we assume a nonrotating isotropic earth. Secondarily, we ignore 
the effect of lateral refraction and assume that the apparent group slowness between earthquake source and seismic station is the average of group slowness along the great-circle path connecting the two points. This statement can be formulated as follows (Satô and Santo, 1969)

$$
t_{E S}(\omega)=\frac{\Delta}{\bar{u}(\omega)}=\int_{E}^{s} \frac{d s}{u(\omega, \theta, \phi)}
$$

where $t_{E S}$ is the travel time of a surface wave between an earthquake $(E)$ and a station $(S), \Delta$ the distance, $\bar{u}$ the average group velocity (or inverse of the average slowness), and the group velocity $u$ is a function of angular frequence $\omega$, colatitude $\theta$, and longitude $\phi$.

We express the group slowness in terms of spherical harmonics

$$
\frac{1}{u(\omega, \theta, \phi)}=\sum_{n=0}^{\infty} \sum_{m=0}^{n}\left[A_{n m}(\omega) \cos m \phi+B_{n m}(\omega) \sin m \phi\right] P_{n}^{m}(\cos \theta)
$$

where $P_{n}^{m}$ is the associated Legendre function. In this study, we truncate the series (2) at $n=n_{0}$. Substituting the truncated form of equation (2) into equation (1), we have

$$
\begin{aligned}
t_{E S}(\omega)=\left[\sum_{n=0}^{n_{0}} \sum_{m=0}^{n} A_{n m}(\omega) \int_{E}^{S} P_{n}^{m}(\cos \theta) \cos m \phi d s\right. & \\
& \left.+\sum_{n=1}^{n_{0}} \sum_{m=1}^{n} B_{n m}(\omega) \int_{E}^{S} P_{n}^{m}(\cos \theta) \sin m \phi d s\right]
\end{aligned}
$$

If the locations of $E$ and $S$ are given, we can calculate numerically the path integrals of the spherical harmonics in equation (3). This equation consitutes an observation equation that relates the coefficients of the spherical harmonics with the travel times. Equation (3) is linear; if a considerable number of observation equations are given, we can determine the coefficients $A_{n m}(\omega)$ and $B_{n m}(\omega)$ for each frequency $\omega$ by a least-squares method. Equation (2) can be used to synthesize the distribution of group velocity $u(\omega, \theta, \phi)$ from the coefficients thus determined.

\section{Group Velocity Measurements}

Moving window analysis (Landisman et al., 1969) has been made for $R_{2}, R_{3}$, and $R_{4}$ phases from 26 earthquakes recorded at the IDA (International Deployment of Accelerograhs, Agnew et al., 1976) gravimeter stations in 1980. Analyzing a synthetic seismogram as an observation, we found that a window length of about 12 times the period is necessary to accurately measure the group velocity of $R_{n}(n \geq 2)$ for periods 100 to $300 \mathrm{sec}$. We used the window length of 12 times the period in this study. In order to increase the resolution for lateral variations of group velocity, we have used mainly $R_{2}$ and $R_{3} . R_{4}$ phases are used only in the case when we cannot use one of $R_{2}$ and $R_{3}$, and the data quality of $R_{4}$ is very good. The 26 earthquakes used in this study are shown in Figure la and are listed in Table 1. In Figure 1a, also shown are the locations of antipodes of the epicenters and the locations of the IDA stations. Figure $1 \mathrm{~b}$ shows the eastern hemisphere poles of great-circle paths for all the earthquake-station pairs used in this study. The figure shows a fairly uniform distribution, although there exists a concentration of poles in middle latitudes. 
Since we adopt the one-station method, we have to correct for instrumental and source group delays in order to make an accurate group velocity measurement. The transfer functions and the constants provided by the IDA project team at the Institute of Geophysics and Planetary Physics, University of California at San Diego, are used in the correction for the instrument. Source group delay estimated from the seismic moment has been used in our study. Kanamori and Given (1982) have made moment tensor inversions for 25 of the 26 earthquakes used in this study. Source process times of the earthquakes are estimated from their seismic moment by using an empirical relation between source process time and seismic moment obtained by Furumoto and Nakanishi (in preparation, 1982). They have determined

TABLE 1

LIST OF EARTHQUAKES (IN 1980) USED*

\begin{tabular}{|c|c|c|c|c|c|c|c|c|c|c|}
\hline \multirow{2}{*}{ No. } & \multicolumn{2}{|c|}{ Date } & \multicolumn{3}{|c|}{ Time } & \multirow{2}{*}{$\begin{array}{c}\text { Latitude } \\
\left({ }^{\circ}\right)\end{array}$} & \multirow{2}{*}{$\begin{array}{c}\text { Longitude } \\
\left({ }^{\circ}\right)\end{array}$} & \multirow{2}{*}{$\begin{array}{c}\text { Depth } \\
(\mathrm{km})\end{array}$} & \multirow{2}{*}{$M_{s}$} & \multirow{2}{*}{ Region } \\
\hline & (m & d) & 1 & $\mathbf{m}$ & s) & & & & & \\
\hline 1 & 1 & 1 & 16 & 42 & 40.0 & $38.815 \mathrm{~N}$ & $27.780 \mathrm{~W}$ & 10 & 6.7 & Azores \\
\hline 2 & 1 & 2 & 20 & 58 & 44.2 & $5.984 \mathrm{~N}$ & $126.188 \mathrm{E}$ & 63 & & Mindanao \\
\hline 3 & 2 & 7 & 10 & 49 & 16.0 & $54.158 \mathrm{~S}$ & $158.890 \mathrm{E}$ & 10 & 6.5 & Macquarie Islands \\
\hline 4 & 2 & 23 & 5 & 51 & 3.2 & $43.530 \mathrm{~N}$ & $146.753 \mathrm{E}$ & 44 & 7.0 & Kurile Islands \\
\hline 5 & 2 & 27 & 21 & 17 & 20.2 & $6.017 \mathrm{~S}$ & $150.189 \mathrm{E}$ & 53 & 6.6 & New Britain \\
\hline 6 & 3 & 8 & 22 & 12 & 10.3 & $22.673 \mathrm{~S}$ & $171.357 \mathrm{E}$ & 38 & 6.7 & Loyalty Islands \\
\hline 7 & 3 & 24 & 3 & 59 & 51.3 & $52.969 \mathrm{~N}$ & $167.670 \mathrm{~W}$ & 33 & 6.9 & Fox Islands \\
\hline 8 & 6 & 9 & 3 & 28 & 18.9 & $32.220 \mathrm{~N}$ & $114.985 \mathrm{~W}$ & 5 & 6.4 & Cal-Mex Border \\
\hline 10 & 6 & 18 & 17 & 14 & 54.5 & $9.475 \mathrm{~N}$ & $126.657 \mathrm{E}$ & 54 & 6.8 & Mindanao \\
\hline 11 & 6 & 25 & 23 & 18 & 20.4 & $5.233 \mathrm{~S}$ & $151.686 \mathrm{E}$ & 49 & 6.5 & New Britain \\
\hline 12 & 7 & 8 & 23 & 19 & 19.8 & $12.410 \mathrm{~S}$ & $166.381 \mathrm{E}$ & 33 & 7.5 & Santa Cruz \\
\hline 13 & 7 & 9 & 20 & 56 & 53.2 & $12.689 \mathrm{~S}$ & $166.004 \mathrm{E}$ & 33 & 6.7 & Santa Cruz \\
\hline 14 & 7 & 14 & 16 & 15 & 1.7 & $29.273 \mathrm{~S}$ & $177.154 \mathrm{~W}$ & 49 & 6.6 & Kermadec \\
\hline 15 & 7 & 17 & 19 & 42 & 23.2 & $12.525 \mathrm{~S}$ & $165.916 \mathrm{E}$ & 33 & 7.9 & Santa Cruz \\
\hline 16 & 7 & 29 & 3 & 11 & 56.3 & $13.101 \mathrm{~S}$ & $166.338 \mathrm{E}$ & 48 & 6.7 & Vanuatu Islands \\
\hline 17 & 7 & 29 & 14 & 58 & 40.8 & $29.598 \mathrm{~N}$ & $81.092 \mathrm{E}$ & 18 & 6.5 & Nepal \\
\hline 18 & 9 & 26 & 15 & 20 & 37.1 & $3.225 \mathrm{~S}$ & $142.237 \mathrm{E}$ & 33 & 6.5 & Papua \\
\hline 19 & 10 & 10 & 12 & 25 & 23.5 & $36.195 \mathrm{~N}$ & $1.354 \mathrm{E}$ & 10 & 7.3 & Algeria \\
\hline 20 & 10 & 24 & 3 & 25 & 34.4 & $21.989 \mathrm{~S}$ & $170.165 \mathrm{E}$ & 33 & 6.7 & Loyalty Islands \\
\hline 21 & 10 & 25 & 7 & 0 & 7.9 & $21.982 \mathrm{~S}$ & $170.025 \mathrm{E}$ & 33 & 6.7 & Loyalty Islands \\
\hline 22 & 10 & 25 & 11 & 0 & 5.1 & $21.890 \mathrm{~S}$ & $169.853 \mathrm{E}$ & 33 & 7.2 & Loyalty Islands \\
\hline 24 & 11 & 8 & 10 & 27 & 34.0 & $41.117 \mathrm{~N}$ & $124.253 \mathrm{~W}$ & 19 & 7.2 & N. California \\
\hline 25 & 11 & 11 & 10 & 36 & 58.2 & $51.422 \mathrm{~S}$ & $28.796 \mathrm{E}$ & 10 & 6.7 & S. Africa \\
\hline 26 & 11 & 23 & 18 & 34 & 53.8 & $40.914 \mathrm{~N}$ & $15.366 \mathrm{E}$ & 10 & 6.9 & Italy \\
\hline 27 & 12 & 17 & 16 & 21 & 58.8 & $49.479 \mathrm{~N}$ & $129.496 \mathrm{~W}$ & 10 & 6.8 & Vancouver Island \\
\hline 28 & 12 & 31 & 10 & 32 & 11.0 & $46.060 \mathrm{~N}$ & $151.453 \mathrm{E}$ & 33 & 6.5 & Kurile Islands \\
\hline
\end{tabular}

* NEIS (National Earthquake Information Service) locations and origin times are used.

the empirical relation $M_{0}=2.5 \times 10^{22} \tau^{3}$ (seismic moment $M_{0}$, dyne $\cdot \mathrm{cm}$; source process time $\tau, \sec$ ) for low-angle thrust earthquakes in the moment range from $10^{27}$ to $10^{30}$ dyne $\cdot \mathrm{cm}$. The moment tensor inversion of the Fox Islands earthquake (event 7 in Table 1) has not been made by Kanamori and Given. Hence, the source process time of this earthquake is estimated from the surface wave magnitude (Kanamori and Given, 1982). The source process times thus estimated for the 26 earthquakes range from 14.7 to $68.7 \mathrm{sec}$. We ignored the directivity of source group delay.

Travel times of Rayleigh waves in the period range from 100 to $298.758 \mathrm{sec}$ were measured by the moving window method; corrections were made for instrumental and source delays, and group velocities were calculated from the distances along the geodesic lines around the geoellipsoid and the corrected travel times. All phases 
analyzed in this study were group velocity windowed with a fixed velocity range from 3.4 to $3.9 \mathrm{~km} / \mathrm{sec}$. Earthquake-station pairs and phases analyzed in this study total 215 and 381, respectively. The group velocities were smoothed by fitting cubic
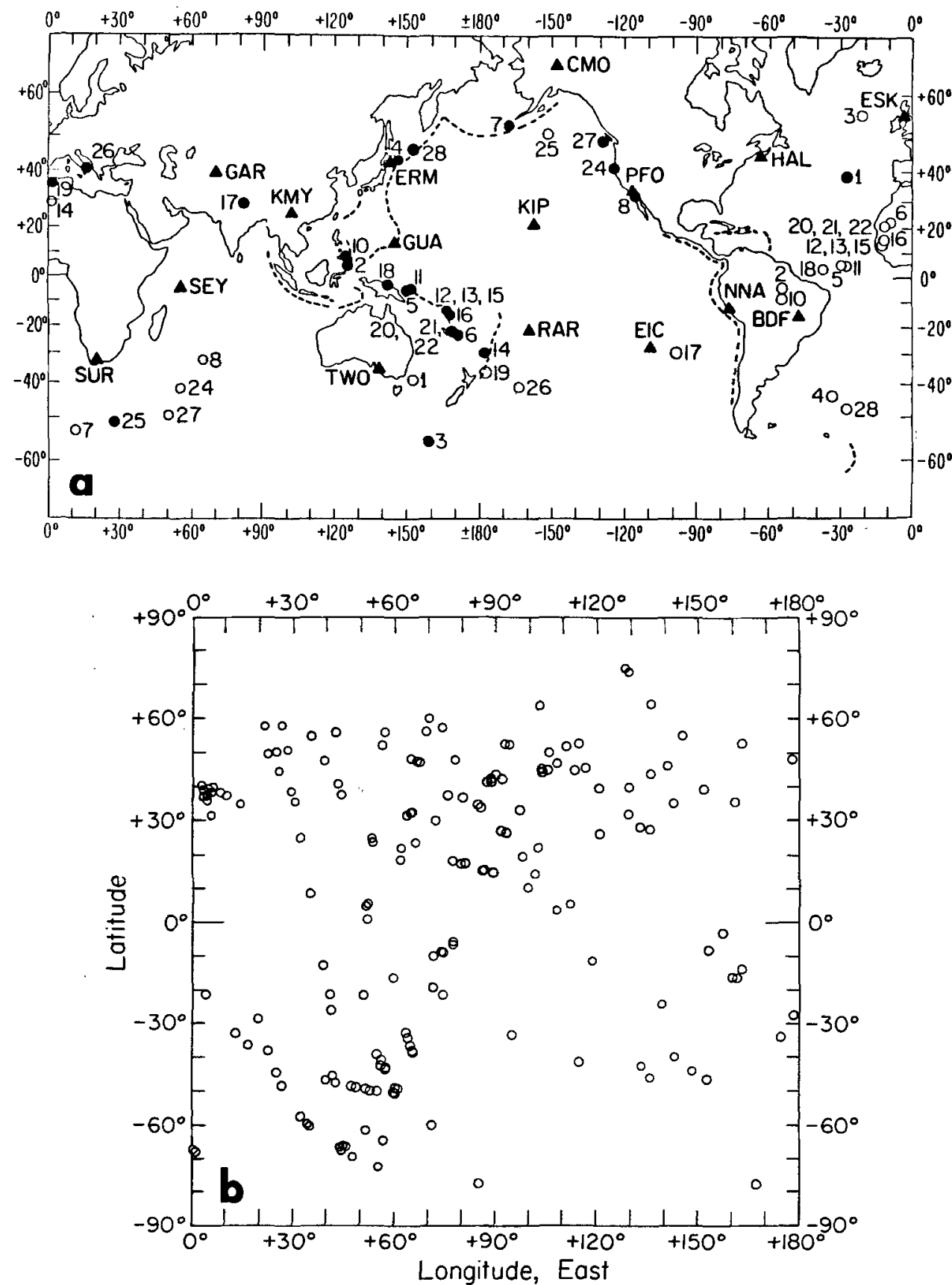

FIG, 1. (a) Locations of epicenters (solid circle), their antipodes (open circle), and IDA stations (solid triangle). (b) Locations of the eastern hemisphere poles of great-circle paths.

polynomials to the deviations of the observed group velocities from the calculated values for earth model PREM (Dziewonski and Anderson, 1981). The smoothing was made by a least-squares fit of a cubic polynomial to 14 data points (see Figure 
5 or Table 2) in the period range from 100 to $300 \mathrm{sec}$. Our group velocity measurements show that PREM is appropriate as an average representation of the observed group velocities except at periods shorter than about $150 \mathrm{sec}$.

\section{RESULTS OF INVERSION}

We solved equation (3) by a least-squares method. Since the observation equation (3) has $\left(n_{0}+1\right)^{2}$, unknowns we have to solve a large normal equation even if $n_{0}$ is not so large. We determined $n_{0}$ considering $\hat{e}_{r m s}^{2}$ defined as follows

$$
\hat{e}_{r m s}^{2}=\frac{\sum_{i=1}^{N_{o b s}}\left(\frac{T_{0}^{i}-T_{e}^{i}}{T_{0}^{i}}\right)^{2}}{N_{o b s}-\left(n_{0}+1\right)^{2}},
$$

where $N_{o b s}$ is the number of observations and $T_{0}^{i}$ and $T_{c}^{i}$ are the observed and synthesized travel times for $i$ th observation. $T_{c}^{i}$ was calculated from equation (3) by using the coefficients $A_{n m}$ and $B_{n m}$ determined. We performed the inversion for $n_{0}$

TABLE 2

Spherically Symmetric Average Rayleigh Wave Group Velocity

\begin{tabular}{rcccc}
\hline No. & $\begin{array}{c}\text { Period } \\
(\mathrm{sec})\end{array}$ & $\begin{array}{c}u_{00} \\
(\mathrm{~km} / \mathrm{sec})\end{array}$ & $\begin{array}{c}u_{P \text { PRM }} \\
(\mathrm{km} / \mathrm{sec})\end{array}$ & $\begin{array}{c}u_{00}-u_{P R E M} \\
(\mathrm{~km} / \mathrm{sec})\end{array}$ \\
\hline 1 & 100.000 & 3.7965 & 3.7529 & 0.0436 \\
2 & 108.783 & 3.7747 & 3.7365 & 0.0382 \\
3 & 118.338 & 3.7536 & 3.7189 & 0.0347 \\
4 & 128.732 & 3.7307 & 3.7007 & 0.0300 \\
5 & 140.040 & 3.7043 & 3.6812 & 0.0231 \\
6 & 152.340 & 3.6794 & 3.6614 & 0.0180 \\
7 & 165.721 & 3.6527 & 3.6396 & 0.0131 \\
8 & 180.277 & 3.6259 & 3.6165 & 0.0094 \\
9 & 196.112 & 3.6010 & 3.5944 & 0.0066 \\
10 & 213.337 & 3.5807 & 3.5760 & 0.0047 \\
11 & 232.076 & 3.5716 & 3.5678 & 0.0038 \\
12 & 252.460 & 3.5849 & 3.5807 & 0.0042 \\
13 & 274.635 & 3.6313 & 3.6275 & 0.0038 \\
14 & 298.758 & 3.7312 & 3.7210 & 0.0102 \\
\hline
\end{tabular}

$=1$ to $10 . \hat{e}_{r m s}^{2}$ decreases slowly in the range $n_{0}=1$ to 7 and then increases. Therefore, we present the results for $n_{0}=7$ in this paper.

Distribution of group velocity over the world, calculated from equation (2), is presented in Figures 2, 3, and 4 for periods 152.34, 196.112, and $252.46 \mathrm{sec}$, respectively. In equation (2), $A_{00}(\omega)$ represents the spherically symmetric average group slowness. Figure 5 shows the spherically symmetric average group velocity $u_{00}(\omega)$ $=1 / A_{00}(\omega)$ in comparison with the group velocity determined by antipodal method (Chael and Anderson, 1982) and that for earth model PREM (Driewonski and Anderson, 1981). Table 2 lists the values of $u_{00}$.

Figure 6 shows the amplitude of harmonics as a function of angular order $n$ for $n$ $=1$ to 7 for periods of $152.34,196.112$, and $252.46 \mathrm{sec}$. The amplitude does not decrease rapidly with increase of angular order. This suggests that there may be higher order lateral variations with considerable power. This might suggest that $n_{0}$ $=7$ adopted in the inversion is not sufficient, and that the slight minimum of $\hat{e}_{r m s}^{2}$ at $n_{0}=7$ is not real.

The distribution of earthquakes and stations gives good coverage for the whole Earth except for the polar regions. Regions such as North America, the central 


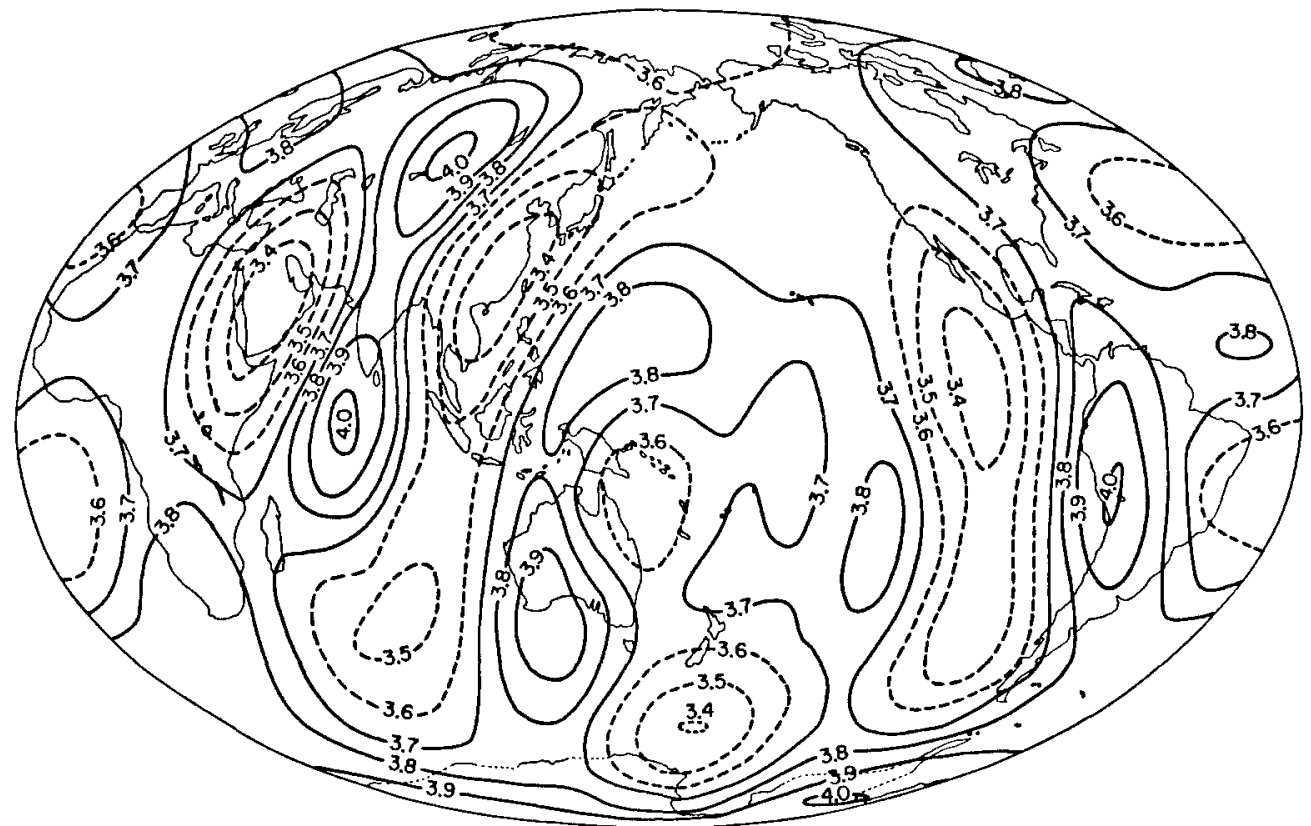

Fig. 2. Synthesized group velocity distribution for a period of $152.34 \mathrm{sec}$. The interval of contour lines $0.1 \mathrm{~km} / \mathrm{sec}$. Solid and dashed contours indicate group velocities higher than $3.7 \mathrm{~km} / \mathrm{sec}$ and lower than $3.6 \mathrm{~km} / \mathrm{sec}$, respectively. $u_{00}$ is $3.679 \mathrm{~km} / \mathrm{sec}$.

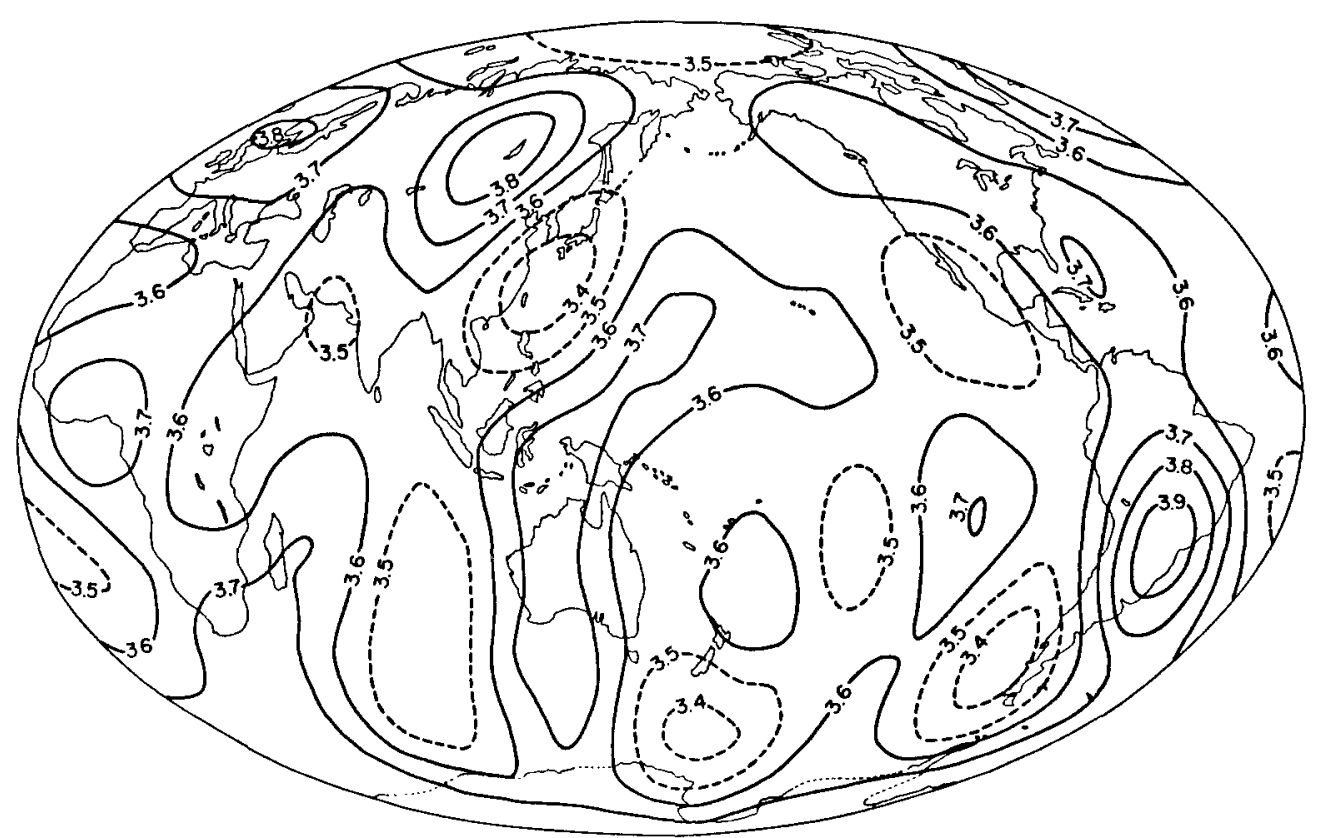

FIG. 3. Synthesized group velocity distribution for a period of 196.112 sec. The interval of contour lines is $0.1 \mathrm{~km} / \mathrm{sec}$. Solid and dashed contours indicate group velocities higher than $3.60 \mathrm{~km} / \mathrm{sec}$ and lower than $3.50 \mathrm{~km} / \mathrm{sec}$, respectively. $u_{00}$ is $3.601 \mathrm{~km} / \mathrm{sec}$.

Atlantic Ocean, the south Indian Ocean, Australia, and the western Pacific and the northeast Pacific are sampled by more than 100 paths. The southern Pacific, Central America-Caribbean, western South America, Africa, Eurasia, the northern Indian 
Ocean, and the northwest Pacific are sampled by 70 to 90 paths. The polar regions, greater than $60^{\circ}$ latitude contain between 20 and 40 paths for each $60^{\circ}$ segment. About 20 paths cross Greenland and adjacent regions. This, and parts of Antarctica, are among the poorest sampled regions. The least sampled equatorial and temperate

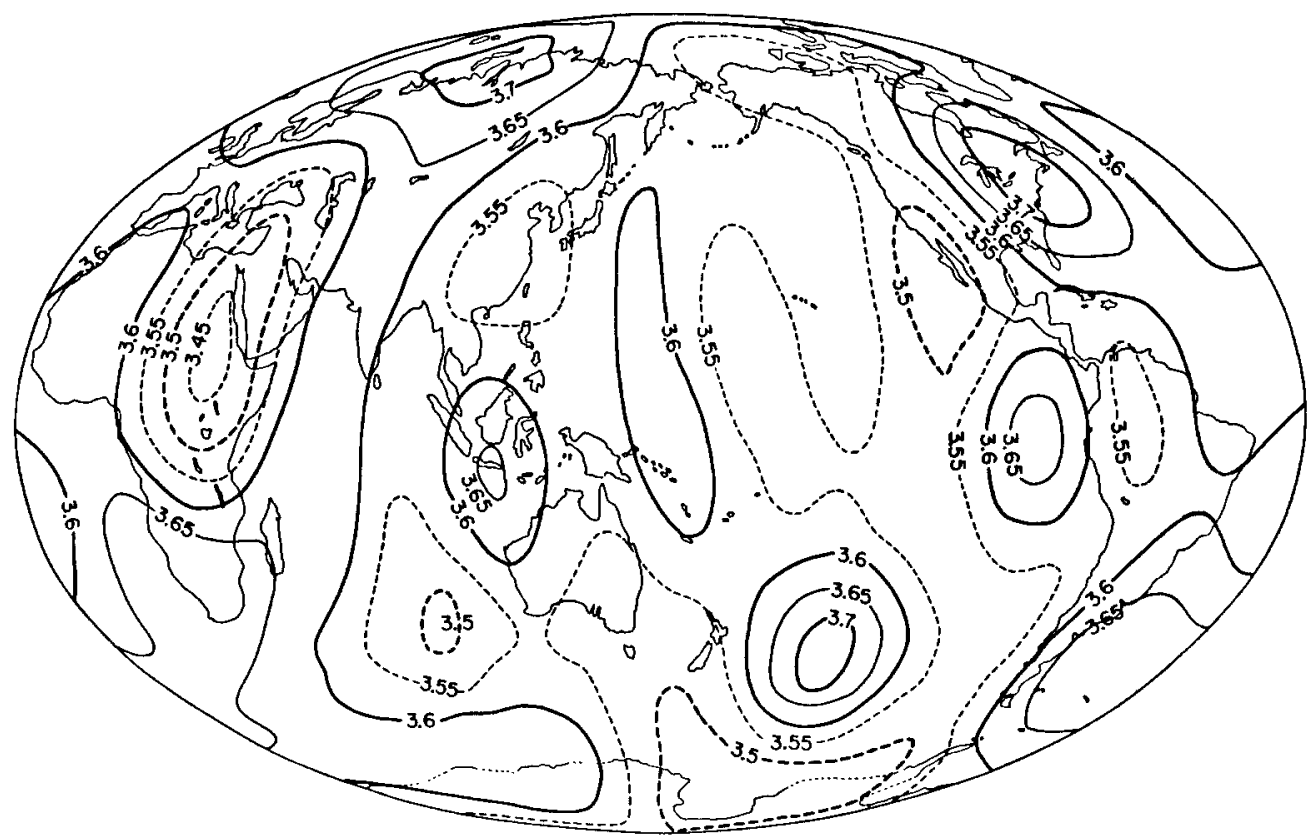

FiG. 4. Synthesized group velocity distribution for a period of $252.46 \mathrm{sec}$. The interval of contour lines is $0.05 \mathrm{~km} / \mathrm{sec}$. Solid and dashed contours indicate group velocities higher than $3.60 \mathrm{~km} / \mathrm{sec}$ and lower than $3.55 \mathrm{~km} / \mathrm{sec}$, respectively. $u_{00}$ is $3.585 \mathrm{~km} / \mathrm{sec}$.

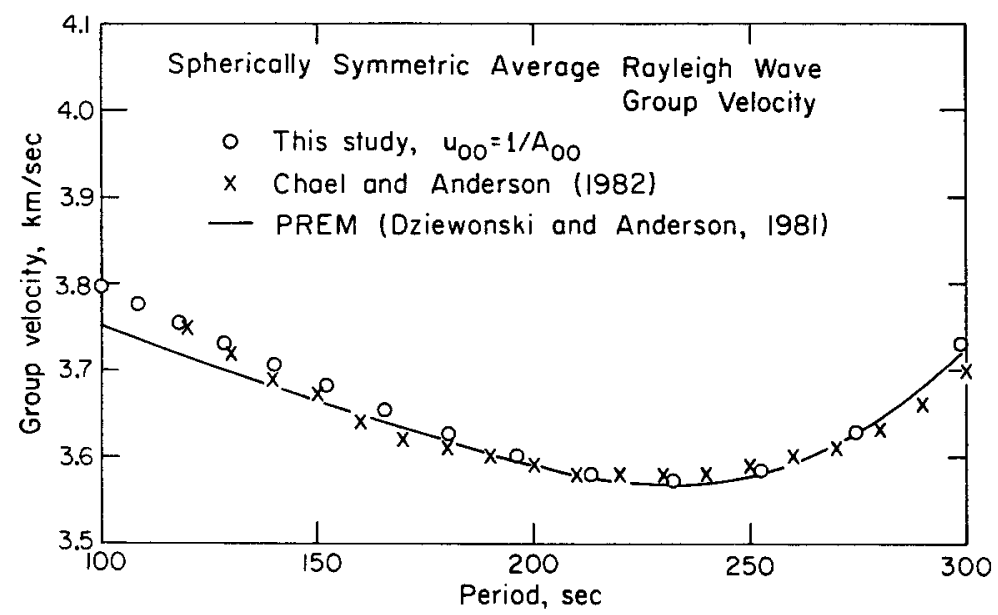

FIG. 5. Spherically symmetric average Rayleigh wave group velocity. $u_{00}$ obtained in this study is compared with the group velocity determined by antipodal method (Chael and Anderson, 1982) and that for model PREM (Dziewonski and Anderson, 1981).

regions are Mexico-Central America-Caribbean and the northern Indian Ocean south of India and Borneo, and surrounding regions but even these are sampled by about 70 paths each. 


\section{Worldwide Distribution of Group Velocity}

A comparison of our spherical harmonic inversion with one of previous pure-path decomposition studies is made in Figure 7. Mills (1978) determined the regionalized group velocities of four tectonic regions using a regionalization model of $\mathrm{Wu}(1972)$. In Figure 7, the group velocities calculated by using equation (2) for the central Pacific $\left(10^{\circ} \mathrm{N}, 170^{\circ} \mathrm{W}\right)$, the central Eurasia $\left(50^{\circ} \mathrm{N}, 90^{\circ} \mathrm{E}\right)$, the Japanese Islands $\left(30^{\circ} \mathrm{N}, 130^{\circ} \mathrm{E}\right)$, and the East Pacific Rise $\left(20^{\circ} \mathrm{N}, 110^{\circ} \mathrm{W}\right)$ are compared with those derived by Mills for the oceanic, continental, island arc, and ridge regions, respectively. Our results show a fairly good consistency with those of Mills at periods shorter than about $250 \mathrm{sec}$, although the former is for particular points and the latter is for particular type regions. Also shown in Figure 7 are the group velocities derived by Forsyth (1975) for the 0 to $20 \mathrm{~m}$.y. zone of the East Pacific Rise. Our results for the East Pacific Rise are in good agreement with his results for periods of 120 and $140 \mathrm{sec}$. For a period of $110 \mathrm{sec}$, our group velocity is about $0.2 \mathrm{~km} / \mathrm{sec}$ lower than his result. This might suggest that we need higher order spherical harmonics to represent the regional variations of group velocity at 110 sec.

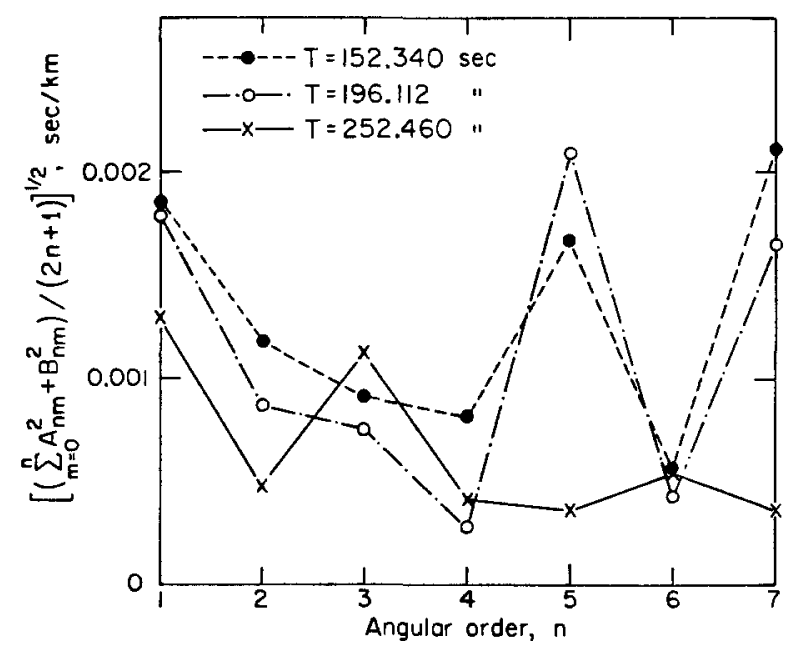

FIG. 6. Amplitude of spherical harmonics as a function of angular order $n$.

Figures 2 and 3 , showing the overall pattern of $u(\theta, \phi)$ determined by our spherical harmonic inversion, for periods of 152.34 and $196.112 \mathrm{sec}$ are in good agreement with the results of previous pure-path and regional studies. A similar correlation is observed at a period of 100 sec. Velocities in tectonically active regions, such as ridges, island arcs, and rifts, are low as compared with $u_{00}$. Those in the shields and the northwestern Pacific are high. Regions of high velocity include central Eurasia, western Australia, Canadian Shield, northern Europe, southern Africa, and central South America. Regions of low velocity include East Africa-Arabia-Red Sea, southeast Asia, northern part of the East Pacific Rise and southern Mexico, Pacific Antarctic Ridge, Macquarie Ridge, and Broken Ridge. Although the pattern changes for period of $252.46 \mathrm{sec}$ (Figure 4), there still remains a regional variation of velocity that correlates with surface tectonics. Since we used spherical harmonics of angular order only up to 7 , the details of lateral variations (higher order heterogeneity) must be missed. Comparing Figures 2 and 3 with the distribution of lithosphere thickness compiled by Pollack and Chapman (1977), one sees a good correspondence between high velocity and thick lithosphere and between low velocity and thin lithosphere. 
This has several implications. First, our results demonstrates that pure-path techniques are a good first-order approximation for studying lateral heterogeneity in the upper mantle. Secondarily, the consistency of the results between spherical harmonic and pure-path inversions suggests that the approach of this study is a promising way for studying regional variations of mantle structure on the global scale as high-quality digital data from IDA, SRO (Seismic Research Observatories), ASRO (Abbreviated Seismic Research Observatories), DWWSSN (Digital WorldWide Standard Seismic Network) stations accumulate. Finally, anomalous regions of the mantle might not be apparent in a priori regionalizations but may show up in studies of this type.

We made several assumptions in inverting the group velocity data to a spherical harmonic representation. We assumed a nonrotating isotropic earth. We approximated the ray path of Rayleigh waves by the geodesic line and the great circle, in group velocity measurements and in spherical harmonic inversion, respectively. Correction for lateral refraction, lateral averaging, rotation, and anisotropy may be

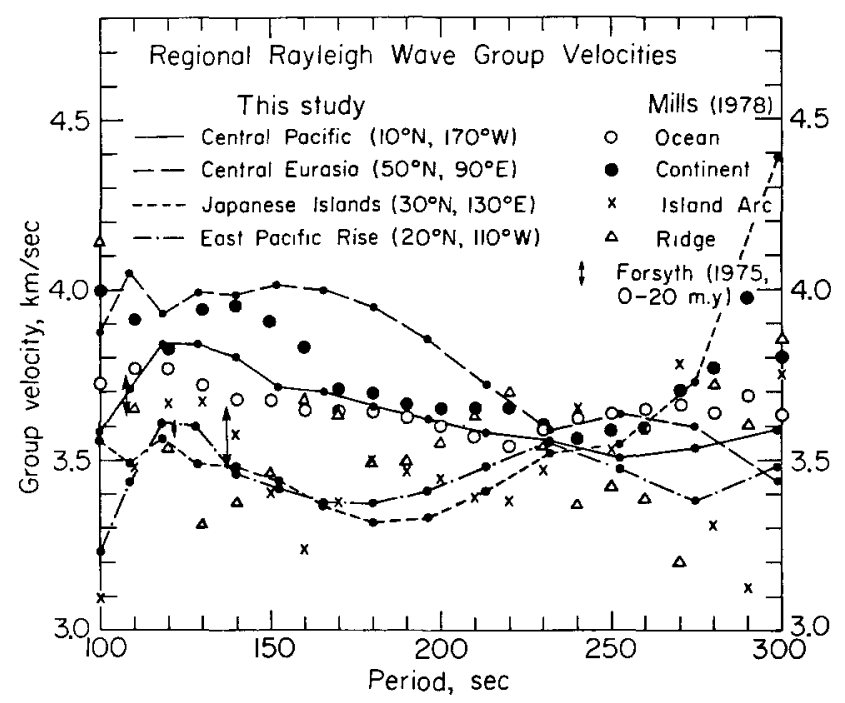

FIG. 7. Regional Rayleigh wave group velocities obtained by the spherical harmonic inversion and pure-path inversions. The results for the pure-path inversions are taken from Forsyth (1975) and Mills (1978).

necessary in order to obtain a more accurate representation of surface wave velocity in terms of spherical harmonics and to construct a three-dimensional model of the Earth's mantle.

\section{CoNCLUSIONS}

We have attempted to determine a spherical harmonic representation of Rayleigh wave group velocity by a least-squares method which does not assume a regionalization of the Earth's surface based on surface geology. The spherical harmonic representation thus determined shows a good consistency with the results of previous pure-path and regional studies, although higher order heterogeneity must be missed in this representation.

\section{ACKNOWLEDGMENTS}

We thank Hiroo Kanamori for allowing us to use his magnetic tape that contains the seismograms used in this study and providing us valuable information on the seismograms and the earthquakes. We 
thank Jeff Given for calculating a synthetic seismogram, which we used to check a computer program and allowing us to use his program that calculates the instrumental response of IDA stations. They kindly made available to us a preprint of their paper on the moment tensor inversion of the earthquakes that are used in this study. We wish to thank Fumiko Tajima for her assistance at all stages of this study. We also thank Ronan Le Bras and Larry Ruff for suggestions. The IDA data used in this study were made available to us by courtesy of the IDA project team at the Institute of Geophysics and Planetary Physics, University of California, San Diego. This research was supported by National Aeronautics and Space Administration (NSG-7610).

\section{REFERENCES}

Agnew, D., J. Berger, R. Buland, W. Farrell, and F. Gilbert (1976). International deployment of accelerometers: a network for very long period seismology, EOS, Trans. Am. Geophys. Union 57, 180-188.

Backus, G. E. (1964). Geographical interpretation of measurements of average phase velocities of surface waves over great circular and great semi-circular paths, Bull. Seism. Soc. Am. 54, 571-610.

Chael, E. P. and D. L. Anderson (1982). Global $Q$ estimates from antipodal Rayleigh waves (submitted for publication).

Chapman, D. S. and H. N. Pollack (1975). Global heat flow: a new look, Earth Planet. Sci. Letters 28, $23-32$.

Dziewonski, A. M. (1971). On regional differences in dispersion of mantle Rayleigh waves, Geophys. J. 22, 289-325.

Dziewonski, A. M. and D. L. Anderson (1981). Preliminary reference Earth model, Phys. Earth Planet. Interiors 25, 297-356.

Forsyth, D. W. (1975). The early evolution and anisotropy of the oceanic upper mantle, Geophys. J. 43, 103-162.

Jordan, T. H. (1978). A procedure for estimating lateral variations from low-frequency eigenspectra data, Geophys. J. 52, 441-455.

Kanamori, H. (1970). Velocity and $Q$ of mantle waves, Phys. Earth Planet. Interiors 2, 259-275.

Kanamori, H. and J. W. Given (1982). Use of long-period surface waves for fast determination of earthquake source parameters. 2. Preliminary determination of source mechanism of large earthquakes $\left(M_{S} \geq 6.5\right)$ in 1980 (submitted for publication).

Landisman, M., A. M. Dziewonski, and Y. Satô (1969). Recent improvements in the analysis of surface wave observations, Geophys. J. 17, 369-403.

Lévêque, J. J. (1980). Regional upper mantle $S$-velocity models from phase velocities of great-circle Rayleigh waves, Geophys. J. 63, 23-43.

Mills, J. M. (1978). Great-circle Rayleigh wave attenuation and group velocity, Part IV: Regionalization and pure-path models for shear velocity and attenuation, Phys. Earth Planet. Interiors 17, 323-352.

Nakanishi, I. (1979). Phase velocity and $Q$ of mantle Rayleigh waves, Geophys. J. 58, 35-59.

Okal, E. A. (1977). The effect of intrinsic oceanic upper-mantle heterogeneity on regionalization of longperiod Rayleigh-wave phase velocities, Geophys. J. 49, 357-370.

Pollack, H. N. and D. S. Chapman (1977). On the regional variation of heat flow, geotherms, and lithospheric thickness, Tectonophysics 38, 279-396.

Satô, Y. (1978). The Theory of Elastic Waves (Dansei-Hado-Ron) (in Japanese), Iwanami-Shoten, Tokyo, $454 \mathrm{pp}$.

Satô, Y. and T. Santo (1969). World-wide distribution of the group velocity of Rayleigh wave as determined by dispersion data, Bull. Earthquake Res. Inst., Tokyo Univ. 47, 31-41.

Toksöz, M. N. and D. L. Anderson (1966). Phase velocities of long-period surface waves and structure of the upper mantle. 1. Great-circle Love and Rayleigh wave data, J. Geophys. Res. 71, 1649-1658.

Wagner, C. A., F. J. Lerch, J. E. Brownd, and J. A. Richardson (1977). Improvement in the geopotential derived from satellite and surface data (GEM 7 and GEM 8), J. Geophys. Res. 82, 901-914.

Wu, F. T. (1972). Mantle Rayleigh wave dispersion and tectonic provinces, J. Geophys. Res. 77, 64456453.

SEISMOlogical Laboratory

Division of Geological and Planetary Physics

California Institute of Technology

Pasadena, California 91125

Contribution No. 3727

Manuscript received 23 December 1981 